\title{
Intake of Sugar-Sweetened Beverage and Metabolic Syndrome Components in Adolescents
}

\author{
Evi Kartini \\ Department of Nutrition Science \\ Faculty of Medicine, Diponegoro \\ University \\ Semarang, Indonesia \\ evikartini10@gmail.com
}

\author{
Fillah Fithra Dieny \\ Department of Nutrition Science \\ Faculty of Medicine, Diponegoro \\ University \\ Semarang, Indonesia \\ fillahdieny@gmail.com
}

\author{
Etisa Adi Murbawanni \\ Department of Nutrition Science \\ Faculty of Medicine, Diponegoro \\ University \\ Semarang, Indonesia \\ etisatitis@gmail.com
}

\author{
A.Fahmy Arif Tsani \\ Department of Nutrition Science \\ Faculty of Medicine, Diponegoro \\ University \\ Semarang, Indonesia \\ fahmi_tsani@yahoo.com
}

\begin{abstract}
Adolescents with metabolic syndrome have a higher risk for cardiovascular diseases and diabetes. Risk factors of metabolic syndrome include central obesity, hypertriglycerid, and hyperglycemia. High intake (>50 g/day) of sugar-sweetened beverages (SSBs) is known to be positively associated with increased waist circumference, triglyceride and fasting blood glucose levels. This study aimed to analyze the relationship between SSBs intake with waist circumference, triglyceride and fasting blood glucose levels in adolescents. This study was a cross-sectional design with fifty-nine subjects of adolescents aged 15-18 years old. They were performed by simple random sampling technique. SSBs and energy intake were assessed with Semi Quantitative Food Frequency Questionnaire, while waist circumference used a tape measure. Blood glucose levels were measured with Glucose Oxidation method, triglyceride levels using colorimetric enzymatic method (GPO-PAP). Data were analyzed by Person Product Moment and Rank Spearman correlation test. High triglyceride levels were observed in $62.7 \%$ subjects and total of $44.11 \%$ subjects had large waist circumference. Excessive intake of SSB was found in $\mathbf{7 2 . 9 \%}$ subjects. Intake of SSBs was correlated with waist circumference $(p=0.020)$ and triglyceride levels $(p=0.044)$, but not fasting blood glucose levels $(p=0.060)$. Consumption of SSBs $>50$ g/day can increased waist circumference and triglyceride levels that were component of metabolic syndrome.
\end{abstract}

Keywords- Sugar-Sweetened Beverage, Metabolic Syndrome, Adolescents

\section{INTRODUCTION}

Metabolic syndrome is a metabolic disorder which increase cardiovascular diseases and diabetes mellitus. The components of metabolic syndrome are central obesity, the increase of triglyceride level and fasting blood glucose, HDL level decrease and also high blood pressure [1]. The increase of metabolic syndrome prevalence on adolescents in line with the increase of obesity prevalence as one or the risk of metabolic syndrome [2]. Based on study result in Semarang city in 2015 showed that the prevalence of metabolic syndrome in obese adolescents as $68.4 \%$ [3]. The research conducted in senior high school students in 2016 showed that from 66 obese adolescents, there were $47.5 \%$ has metabolic syndrome [4].

Obesity is the main trigger of metabolic syndrome, because excess calorie intake from carbohydrate, fat, and protein more than total energy needed [5]. The excess energy will be convert into fat and stored in adipose tissue which will increase waist circumference [6]. Adolescents with central obesity has waist circumference for more than 80th percentile. Obesity can trigger the increase of triglyceride by excess fat storing. Triglyceride accumulation in hepar can cause insulin resistance which will increase fasting blood glucose [3].

Consumption SSBs increases on adolescents because it is affected by several factors, those are: advertisements broadcasted in media, peer group influences, and distribution of SSBs in accessible cafeteria or supermarket [7], [8]. Sugarsweetened beverage is a beverage of which has been added calorie sweetener into it, such as soft drink, sport drink, fruit drink, energized drink, tea and coffee, milk, fruit juice, and isotonic beverage [9]. Based on the study of cohort conducted on adolescents showed that the consumption of SSBs for 375 $\mathrm{ml}$ which contain sugar approximately 37-54 g contribute energy as 150 calories which related to the increase of metabolic syndrome risk [10], [11]. The additional sugar content in SSBs contributes energy as $21.2 \%$ on adolescents which can increase obesity Excess energy in the body will be stored in a form of triglyceride in depose tissue which lead to obesity if it is occur continuously [12], [13]. The study on female adolescents aged 12-19 showed the consumption of SSBs $250 \mathrm{~g} /$ day will lead to the increase of triglyceride as $2,3 \mathrm{mg} / \mathrm{dL}$ [14]. Another study stated that the consumption of $\mathrm{SSBs}>1$ portion/ day can increase the prevalence of diabetes mellitus type 2 as $26 \%$ [15]. Based on the background the author interested to analyze the correlation of SSBs intake with waist circumference, triglyceride and fasting blood glucose on adolescents.

\section{MATERIALS AND METHODS}

This study used a cross sectional design with data collecting on July until August 2017. This study was 
conducted on students in SMA Negeri 15 semarang. The selection of 59 subjects was performed by simple random sampling technique. Data on age, subjects identity, antropometri, sugar sweetened beverage (SSBs) intake, energy intake, waist circumference, triglyceride levels, and fasting blood glucose levels.

Waist circumference was the circle line of a waist right on navel measured through the middle of lowest interior edge with crista iliaca. The category of central obese waist circumference if the waist circumference was more than 80 $\mathrm{cm}$ and normal if it less than 80. Fasting blood glucose levels (GDP) are a parameter that describes the glucose concentration in the blood plasma measured in subjects who were fasting for 8-12 hours. GDP levels were measured using spectophotometry by the Glucose Oxidation (GOD) method. GDP levels are considered to be high if it is $\geq 100 \mathrm{mg} / \mathrm{dL}$ and normal if it is $\leq 100 \mathrm{mg} / \mathrm{dL}$. Triglyceride was one of the fats in the bloodstream that come from fat intake and were formed in the liver. Triglyceride levels were measured by enzymatic colorimetric using glycerol phosphate oxidase (GPO). Triglyceride levels was considered high if it was $\geq 110 \mathrm{mg} / \mathrm{dL}$ and normal if it is $<110 \mathrm{mg} / \mathrm{dL}$ [16].

Sugar-sweetened beverage intake was the average of sugar from packaged and non-packaged beverages. Packaged beverages are processed drinks containing additional sugars recorded on the nutritional fact label on the packaging, whereas non-packaged beverages are sugar-added drinks during brewing and are not recorded on the nutritional fact label on the packaging. Sugar was calculated from the sugar content contained on the package and added sugar during brewing. Measurement of SSBs intake was obtained by semi quantitative consumption frequency method with frequency question of consumption in a day, week, month, and year and the amount of each time consumption was recorded in household size (URT) and converted to gram. The intake of SSBs was classified as high if it contains sugar $\geq 50 \mathrm{~g} /$ day and as normal if it was $<50 \mathrm{~g} /$ day [17]. The energy of SSBs intake was categorized to be high if it was $\geq 10 \%$ of total energy intake and as a normal if it was $<10 \%$ of total energy intake [18]. Data of energy intake obtained by interview using Semi Quantitative Food Frequency Questionnaire (SQ-FFQ). Energy requirements were calculated based on individual needs and then the energy intake was grouped into the adequacy level based on the National Widyakarya Food and Nutrition (WNPG) 2012. The intake of $\geq 120 \%$ of individual needs was categorized as high, $90-119 \%$ is sufficient, and $<90 \%$ is less. Data were analyzed by Person Product Moment and Rank Spearman correlation test. Data analysis using SPSS with $95 \%$ confidence degree $(\alpha=0,05)$.

\section{RESULTS AND DISCUSSIONS}

The subjects aged 15-18 years old including 35 (60\%) were female subject and $24(40 \%)$ male subject. The results in Table 1 show that the average age of the subjects was 16.2 years old and there were subjects with z-score of body mass index for age of 4.9 SD who fall into the obesity category.
Table 1: Characteristic of Subject

\begin{tabular}{lrrr}
\hline Variables & Minimum & Maximum & Mean+DS \\
\hline Age (years) & 15 & 18 & $16,2 \pm 0,7$ \\
Height (cm) & 145,0 & 183,0 & $160,2 \pm 7,4$ \\
Weight (kg) & 35,9 & 141,0 & $63,2 \pm 19,1$ \\
BMI/age (SD) & $-2,7$ & 4,9 & $0,7 \pm 1,5$ \\
Intake of SSBs (g/day) & 11,8 & 236,2 & $92,5 \pm 60,8$ \\
SSBs packaging (g/day) & 4,6 & 198,2 & $62,1 \pm 46,3$ \\
SSBs non-packaging (g/day) & 1,7 & 89,6 & $30,3 \pm 25,2$ \\
Energy Intake of SSBs (kcal/day) & 72,4 & 1516,0 & $520,5 \pm 328,3$ \\
Energy Intake of SSBs (\% Energy) & 3 & 41,2 & $19,2 \pm 8,7$ \\
Energy Intake (kcal/day) & 1171,9 & 6327,7 & $2707,2 \pm 1037,9$ \\
Waist circumference (cm) & 56,5 & 114,7 & $79,9 \pm 12,6$ \\
Triglyceride (mg/dL) & 96,0 & 150,0 & $113,9 \pm 10,3$ \\
Fasting Blood Glucose Levels (mg/dL) & 70,0 & 98,0 & $81,5 \pm 7,6$ \\
\hline
\end{tabular}

The intake of sugar-sweetened beverage subjects ranged from 11.8-236.2 g/day with an average SSBs intake greater than non-packaged beverage, i.e. $62.1 \mathrm{~g} /$ day and 30.3 g/day. While the mean SSBs intake of $92.5 \mathrm{~g} /$ day, which means the consumption of SSBs in the subject tends to be high. The mean triglyceride and fasting blood glucose levels were $113.9 \mathrm{mg} / \mathrm{dL}$ and $81.5 \mathrm{mg} / \mathrm{dL}$, respectively, high triglycerides and normal at fasting blood glucose levels.

Table 2 shows that $72,9 \%$ subjects were high intake of SSB, but subjects with sufficient energy intakes were only $28.8 \%$, but $91.5 \%$ of subjects took energy from a high sugarsweetened beverage (>10\% of total energy). The high intake of sugar-sweetened beverage is in line with energy intake in the subject, where found in $49.2 \%$ of subjects who have higher energy intake. The average total SSBs intake was $\pm 19.2 \%$ of total energy intake.

Table 2. Characteristics of Sugar-Sweetened Beverage and Energy Intakes

\begin{tabular}{|c|c|c|c|}
\hline \multirow{2}{*}{$\begin{array}{l}\text { Category of SSBs and } \\
\text { energy inatake }\end{array}$} & \multicolumn{2}{|c|}{ Sex } & \multirow{2}{*}{$\begin{array}{l}\text { Total } \\
\mathrm{n}(\%)\end{array}$} \\
\hline & $\begin{array}{l}\text { Male } \\
\mathrm{n}(\%)\end{array}$ & $\begin{array}{c}\text { Female } \\
\mathrm{n}(\%)\end{array}$ & \\
\hline \multicolumn{4}{|l|}{ Sugar Sweetened } \\
\hline Beverage (g) & $6(10,2)$ & $10(16,9)$ & $16(27,1)$ \\
\hline Sufficient & $18(30,5)$ & $25(42,4)$ & $43(72,9)$ \\
\hline High & & & \\
\hline \multicolumn{4}{|l|}{ Energy intake from } \\
\hline SSBs $(\%)$ & $1(1,7)$ & $4(6,8)$ & $5(8,5)$ \\
\hline $\begin{array}{l}\text { Sufficient } \\
\text { High }\end{array}$ & $23(39,0)$ & $31(52,5)$ & $54(91,5)$ \\
\hline \multicolumn{4}{|l|}{ Energy intake $(\%)$} \\
\hline Less & $7(11,9)$ & $6(10,2)$ & $13(22,1)$ \\
\hline Sufficient & $8(13,5)$ & $9(15,3)$ & $17(28,8)$ \\
\hline High & $9(15,3)$ & $20(33,9)$ & $29(49,2)$ \\
\hline
\end{tabular}

This result is greater than the results of a survey conducted by Centers for Disease Control and Prevention (CDC) in children and adolescents in the United States in 2005-2008, the average intake of sugar from foods and beverages by $16 \%$ of total energy intake [19]. The study conducted on adolescents aged 12-14 years old in 2014 stated that the average sugar consumption in beverages sweetened was $60.43 \mathrm{~g}$ (19.04\% of total energy) [20]. In fact, the suggestion of 50-60\% of energy needs obtained from sources of carbohydrates, both complex and simple. However, according to Tumpeng Gizi Seimbang (TGS) Indonesia, the greatest fulfillment of needs is derived from complex carbohydrate sources, such as whole grains, cereals, various 
tubers and their processed products. Whereas simple carbohydrate fulfillment is limited for no more than $50 \mathrm{~g} /$ day or $<10 \%$ of total energy intake [17] [18] [21].

Sugar-sweetened beverage consumption that tends to be high in adolescents is affected by several factors, such as advertisements that are widely broadcasted in the media, the distribution of SSBs in cafeterias or accessible supermarkets, as well as the influenced by peers. The choice of baverage and eating habits on adolescents is influenced by peer because it is considered as the solidarity of the peers [7] [8]. The most commonly consumed type of SSBs was the type of package beverage, which is tea, milk drinks, fruit drinks, and soft drinks which contribute an average of sugar 20-46 g/package as well as non-packaged beverages such as tea and various kinds of ice that has average sugar content of 22-26 g/serving or equivalent to \pm 2 tbsp sugar.

Table 3 shows that 14 subjects were classified as obese based on body mass index for age, meanwhile $44.1 \%$ subjects were abdominal obesity, $62.7 \%$ of subjects had hypertriglyceride and $44.1 \%$ subjects had central obesity. The prevalence of obesity in this study was higher than that of the study in 2016, which was $12.8 \%$ [4]. The increased of obesity, especially central obesity is closely related to the incidence of metabolic syndrome. Adolescents who fulfill two components of the metabolic syndrome include pre-metabolic syndrome, most of which already occur in the subject, including high waist circumference and high triglyceride levels. Adolescents with pre-metabolic syndrome are at greater risk for becoming metabolic syndrome than with normal adolescents [22]. Subjects classified as central obese $(\geq 80$ th percentile) was $44.1 \%$, with female subjects as $(28.8 \%)$ was greater than female $(15.3 \%)$.

Table 3. Nutritional status, and component of metabolic syndrome in subjects

\begin{tabular}{lccc}
\hline \multirow{2}{*}{ Metabolic syndrome components } & \multicolumn{2}{c}{ Sex } & \multirow{2}{*}{$\begin{array}{c}\text { Total } \\
\mathrm{n}(\%)\end{array}$} \\
\cline { 2 - 3 } & $\begin{array}{c}\text { Male } \\
\mathrm{n}(\%)\end{array}$ & $\begin{array}{c}\text { Female } \\
\mathrm{n}(\%)\end{array}$ & \\
\hline Nutritional status & & & \\
Thin & - & $2(3,4)$ & $2(3,4)$ \\
Normal & $13(22,0)$ & $21(35,6)$ & $34(57,6)$ \\
Overweight & $3(5,1)$ & $6(10,2)$ & $9(15,3)$ \\
Obese & $8(13,5)$ & $6(10,2)$ & $14(23,7)$ \\
Waist circumference (cm) & & & \\
Normal (< persentil 80) & $15(25,4)$ & $18(30,5)$ & $33(55,9)$ \\
Abdominal obesity ( $\geq$ persentil 80$)$ & $9(15,3)$ & $17(28,8)$ & $26(44,1)$ \\
Fasting Blood Glucose Levels & & & \\
(mg/dL) & $24(40,7)$ & $35(59,3)$ & $59(100)$ \\
Normal (<100 mg/dL) & & & \\
Triglyceride Levels (mg/dL) & & & \\
Normal (<110 mg/dL) & $8(13,6)$ & $14(23,7)$ & $22(37,3)$ \\
High $(\geq 110$ mg/dL) & $16(27,1)$ & $21(35,6)$ & $37(62,7)$ \\
\hline
\end{tabular}

This result is in accordance with the study of 13-15 years old adolescents in Semarang which stated that the incidence of central obesity in female is greater than male that were $52.6 \%$ and $38.6 \%$ [3]. This is because female body fat composition is greater than male, ranging from $21-35 \%$ as well as women's physical activity tend to be lower than men, so that the excess energy consumed more easily converted into fat and accumulate faster [23].
Central obesity in individuals due to body fat stores and intra-abdominal fat is closely related to metabolic abnormalities and cardiovascular disease [24]. Adipose tissue is a tissue that plays an active role in the release of free fat and pro and anti-inflammatory cytokines, so that obese individuals tend to experience cholesterol homeostasis disorders, which one of which was elevated triglyceride levels [25]. In this study there were subjects with hypertriglyceride of $62.7 \%$. This number is higher than the research in 2016, which is $37.5 \%$ [4]. The increase of components of the metabolic syndrome, one of which is obesity in adolescence occurs due to many factors, one of which is excessive food intake and low physical activity.

\section{The Correlation of SSBs and energy intake with Metabolic Syndrome Components}

Table 4 shows that there was significant correlation between SSBs intake with waist circumference $(p=0.015)$ and triglyceride levels $(\mathrm{p}=0.044)$, as well as energy intake ( $\mathrm{p}=$ 0.014 ) with triglyceride levels on adolescents. But there was no significant correlation of SSBs intake with fasting blood glucose levels in adolescents $(\mathrm{p}=0.06)$.

Table 4. Sugar-Sweetened Beverage Intake with Waist circumference, Triglyceride Levels, and Fasting Blood Glucose Levels

\begin{tabular}{|c|c|c|c|c|c|c|}
\hline \multirow[t]{2}{*}{ Variabel } & \multicolumn{2}{|c|}{$\begin{array}{l}\text { Waist } \\
\text { circumference }\end{array}$} & \multicolumn{2}{|c|}{$\begin{array}{l}\text { Triglyceride } \\
\text { Levels }\end{array}$} & \multicolumn{2}{|c|}{$\begin{array}{l}\text { Fasting Blood } \\
\text { Glucose Levels }\end{array}$} \\
\hline & $\mathrm{r}$ & $p$ & $\mathrm{r}$ & $p$ & $\mathrm{r}$ & $p$ \\
\hline $\begin{array}{l}\text { Intake of } \\
\text { Sugar Sweetened } \\
\text { Beverage (SSBs) (g) }\end{array}$ & 0,302 & $0,020^{\mathrm{a}}$ & 0,264 & $0,044^{\mathrm{a}}$ & 0,246 & $0,060^{\mathrm{a}}$ \\
\hline Energy (kcal) & 0,208 & $0,113^{\mathrm{b}}$ & 0,318 & $0,014^{\mathrm{b}}$ & 0,043 & $0,745^{\mathrm{b}}$ \\
\hline
\end{tabular}

This result same with study conducted on adolescents aged 12-16 in Taiwan who stated that SSBs intake associated with an increased component of the metabolic syndrome [14].

Sugar-sweetened beverage can increase waist circumference because the excess energy from SSBswill be stored in a form of fat inside of body and then it was stored as energy storage in diposa tissue. After that the energy intake from sugar-sweetened beverage is known as liquid form which does not give the effect of full in stomach compare to solid food, therefore will increase excess energy intake. In addition, the fructose content in Sugar-sweetened beverage does not stimulate leptin, hence people who consume high fructose will complain to be hungry faster and eat excessively which will increase the fat accumulation intra abdominal over weight [26] [27]. This is in line with the study conducted to children aged 3-11 years old in England in 2004 and adolescents 12-18 years old in Taiwan in 2014 that high intake of SSBs can increased Body mass Index (BMI) and waist circumference [14] [28]. The increase of triglyceride levels may occur due to the fructose content present in SSBs. As much as $60 \%$ of the carbohydrates used as sweeteners in SSBs are fructose that will largely be metabolized in the liver. The first working enzyme is fructokinase or ketoheksokinase (KHK-C) using adenosine tri phosphate (ATP) to phosphorylate fructose to fructose -1 
phosphate. Then the fructose-1 phosphate was converted to dihydroxyacetone phosphate and glyceraldehyde 3-phosphate which is the material to form glycerol 3-phosphate and acetylKoA. Furthermore, acetyl-KoA was converted to acyl-KoA which binds to glycerol-3 phosphate to form triacyl glycerol or triglyceride. The cross-sectional study of adolescents in the UK in 2011 suggests that consuming high intake SSBs may increase triglyceride levels as well as the risk of cardiovascular disease [29]. A cohort study in children aged 815 years also mentions that the intake of SSBs was positively associated with triglyceride levels [30].

This study showed that no correlation of SSBs intake with fasting blood glucose levels in adolescents ( $p>0.05$ ). These results are supported by study conducted on obese adolescets showing no association between intake of sweet beverage with fasting blood glucose levels [31]. The absence of sugar-sweetened beverage intake link with fasting blood glucose levels in this study because all subjects had fasting blood glucose levels in the normal category, so it cannot give an idea of the relationship of SSBs intake with fasting blood glucose levels. This result is supported by a Brazilian study in 2013 which states that hyperglycemia in adolescents has the smallest percentage, which is $2 \%$ [32]. Moreover, fasting blood glucose indicator is more describing if it was conducted on subjects with overweight conditions, has a family history of type 2 diabetes mellitus, and have signs of insulin resistance or conditions associated with insulin resistance [33]. The normal fasting blood glucose levels in adolescents show because the body's compensating system is still good so the body can maintain normal blood glucose levels through the hormone insulin secreted by the pancreas [34]. Based on the correlation test, the intake of SSBs showed a positive correlation with fasting blood glucose, which means higher SSBs intake then fasting blood glucose level will be higher. This is in line with a cross-sectional study conducted on children and adolescents claiming that sugar intake from beverages can increase fasting blood glucose levels [11] [35]. Sugar-sweetened beverage contains more easily absorbed simple carbohydrates such as sucrose fructose corn syrup (HFCS) on a high-glycemic index diet which would then increase appetite. and weight gain associated with the development of glucose intolerance and insulin resistance [36]. In addition, the fructose used as a sweetener in SSBsalso contributes to the failure of glucose tolerance and insulin resistance through the mechanism of de novo lipogenesis (DNL). Fructose induces DNL by providing carbon atoms (glycerol 3 phosphate and acyl-KoA) converted into monoacylglycerol and diacylglycerol (DAG) which were subsequently converted to triglycerides. The accumulation of triglycerides in the liver will result in insulin resistance [37].

\section{CONCLUSION}

Most of the subjects in this study had a high energy eating habits (49.2\%), and consumed a high sugar beverage (72.9\%). The average sugar intake in drinks reached 92.5 g/day (19.2\% of total energy). So that found $44.1 \%$ subjects have experienced central obesity and $62.7 \%$ have hyper triglyceride which is a component of metabolic syndrome. Adolescents need to be educated regarding the limit of consuming SSBs maximum $250-350 \mathrm{~mL} / \mathrm{day}$ or additional sugar to foods and beverage $<50 \mathrm{~g} /$ day $(<4$ tbsp/day) and offset by physical activity for achieving an energy balance and lowering the risk of metabolic syndrome.

\section{REFERENCES}

[1] Alberti KGMM, Eckel RH, Grundy SM, Zimmet PZ, Cleeman JI, Donato KA, et al. Harmonizing the Metabolic Syndrome: A Joint Interim Statement of the International Diabetes Federation Task Force on Epidemiology and Prevention; National Heart, Lung, and Blood Institute; American Heart Association; World Hearth Federation; International Atheroclerosis Society; and International Association for the Study of Obesity. Circulation. 2009;120:1640-1645

[2] Weiss R, Dziura J, Burgert TS, Tamborlane WV, Taksali SE, Yeckel $\mathrm{CW}$, et al. Obesity and the Metabolic Syndrome in Chldren and Adolescents. New England Journal of Medicine. 2004;350:2362-2374

[3] Dieny FF, Widyastuti N, Fitranti DY. Metabolic Syndrome among Adolescents Obese: Prevalence and Relation with Diet Quality. Indonesian Journal Clinical of Nutrition. 2015;12 (1) : 1-11

[4] Muhammad D, Dieny FF. Intake of Vitamins A, C, and E with the Incidence of Metabolic Syndrome in Adolescent Obese. Journal of Nutrition College. 2016;5(4):289-297

[5] Santos A-C, Lopes C, Guimaraes J, Barros H. Central obesity as A Major Determinant of Increased High-Sensitivity C-reactive Protein in Metabolic Syndrome. International Journal of Obesity. 2005;29:14521456

[6] Oktaviani WD, Saraswati LD, Rahfiludin MZ. Fast Food Consumption Habits, Consumption Patterns, Characteristics of Youth and Parents with Body Mass Index (BMI). Public Health Journal.. 2012;1(2):542-553

[7] Robert Wood Johnson Foundation. Food and Beverage Marketing to Children and Adolescents: An Environment at Odds with Good Health. Healthy Eating Research. 2011:1-11

[8] Flood JE, Roe LS, Rolls BJ.The Effect of Increased Beverage Portion Size on Energy Intake at A Meal. Journal of the Academy of Nutrition and Dietetics.2006;106:1984-1990

[9] Centers for Disease Control and Prevention. The CDC Guide to Strategies for Reducing the Consumption of Sugar Sweetened Beverage (SSBs). 2010: 1-41

[10] Barrio-Lopez MT, Martinez-Gonzales MA, Fernandez-Montero A, Beunza JJ, Zazpe I, Bes-Rastrollo M. Prospective Study of Changes in Sugar-Sweetened Beverage Consumption and the Incidence of the Metabolic Syndrome and Its Components: the SUN cohort. British Journal of Nutrition. 2013;(110):1722-1731

[11] Wang J. Consumption of Added Sugars and Development of Metabolic Syndrome Components Among A Sample of Youth At Risk of Obesity. McGill University; 2013:1-244

[12] Barquera S, Hernandez-Barrera L, Tolentino ML, Espinosa J, Ng SW, Rivera JA, et al. Energy Intake from Beverages is Increasing among Mexican Adolescents and Adults. Journal of Nutrition. 2008; 138: 24542461

[13] Febriyani NMPS, Hardinsyah, Briawan D. Calorie Drinks and Its Contribution to Total Energy Intake in adolescents and adults. Journal of Nutrition and Food.. 2012; 7(1): 35-42

[14] Chan T-F, Lin W, Chen Y-L, Huang H-L, Yang W-Z, Lee C-Y, et al. Elevated Serum Triglyceride and Retinol-Binding Protein 4 Levels Associated with Fructose-Sweetened Beverages in Adolescents. Plos One Journal. 2014;9(1): 1-9

[15] Malik VS, Hu FB. Sweeteners and Risk of Obesity and Type 2 Diabetes: The Role of Sugar-Sweetened Beverages. Springer Link Journal. 2012; 12: 195-203. 
[16] Pulungan AB, Marzuki AN, Julia M, Rosaliana I, Damayanti W, Yanuarso P et al. Diagnosis and Management of Metabolic Syndrome in Children and Adolescents. Consensus of Indonesian Pediatric Association. 2014;1-25

[17] Ministry of Health of the Republic of Indonesia. Regulation of the Minister of Health of the Republic of Indonesia concerning Inclusion of Sugar, Salt and Fat Content Information and Health Message for Prepared Food and Ready Food. Jakarta; 2013.

[18] World Health Organization. Guideline: Sugars Intake for Adults and Children. Geneva; 2015 p. 1-46

[19] Ervin RB, Kit BK, Carroll MD, Ogden CL. Consumption of Added Sugar Among U. S. Children and Adolescents, 2005-2008. U.S Department of Healh and Human Services. 2012;(87):2005-2008

[20] Akhriani M, Fadhilah E, Kurniasari FN. The relationship of consumption of sweetened beverages with overweight among students in SMP Negeri 1 Bandung. Indonesian Journal of Human Nutrition. 2015;1(1):57-70

[21] Ministry of Health of the Republic of Indonesia. Balanced Nutrition Guidelines. Jakarta; 2014.

[22] Widyastuti N, Dieny FF, Fitranti DY. Saturated Fat and Fiber Intake in Adolescent Obesity; Associated with Metabolic Syndrome. Indonesian Journal of Clinical Nutrition. 2016;12(4):131-137

[23] Piche M-E, Weisnagel SJ, Corneau L, Nadeau A, Bergeron J, Lemieux S. Contribution of Abdominal Visceral Obesity and Insulin Resistance to the Cardiovascular Risk Profile of Postmenopausal Women. American Diabetes Association. 2005;54(March):770-777

[24] Rodriguez G, Moreno L, Blay M, Blay V, Garagorri J, Bueno M. Body Composition in Adolescents: Measurements and Metabolic Aspects. International Journal of Obesity. 2004;28:54-58

[25] Taverne F, Richard C, Couture P, Lamarche B. Abdominal Obesity, Insulin Resistance, Metabolic Syndrome and Cholesterol Homeostasis. Pharma Nutrition. 2013;1(4):130-136

[26] Pereira MA. Sugar-Sweetened and Artificially-Sweetened Beverages in Relation to Obesity Risk. Am SocNutr. 2014;797-808

[27] Shapiro A, Mu W, Roncal CA, Cheng KY, Johnson RJ SP. FructoseInduced Leptin Resistance Exacerbates Weight Gain Inresponse to Subsequent High Fat Feeding. American Journal Physiology Regulation Integrative and Comparative Physiology. 2008;1370-1375
[28] Kosova EC, Auinger P, Bremer AA. The Relationship between SugarSweetened Beverage Intake and Cardiometabolic Markers in Young Children. Journal of Academy of Nutrition Dietetic. 2014;113(2):219227

[29] Rompay MI Van, Mckeown NM, Goodman E, Eliasziw M, Chomitz VR, Gordon CM, et al. Sugar-Sweetened Beverage Intake is Positively Associated with Baseline Triglyceride Concentrations, and Changes in Intake Are Inversely Associated with Changes in HDL Cholesterol over 12 Months in a Multi-Ethnic Sample of Children. The Journal of Nutrition. 2015;145:2389-2395

[30] Welsh JA, Sharma A, Argeseanu S, Vos MB. Consumption of Added Sugars and Cardiometabolic Risk Indicators Among US Adolescents. Circulation Journal National Institutes of Health. 2014;123(3):249-257

[31] Sudono PP, Sulistyoningrum DC, Tsani AFA. The Relationship between Sweet Drinks to Blood Sugar Levels in Adolescent Obesity in the Yogyakarta. Universitas GadjahMada; 2015

[32] Park HS, Oh SW, Cho S, Choi WH, Kim YS. The Metabolic Syndrome and Associated Lifestyle Factors Among South Korean Adults. Interhational Journal of Epidemiology. 2004;33(2):328-336

[33] Mittal S. The Metabolic Syndrome in Clinical Practice. Inggris: Springer; 2008. P. 226

[34] Buse JB, Kenneth SP, Charles FB. Type 2 Diabetes Mellitus. William Textbook of Endocrinology. 2002;1427-1451

[35] Wang YC, Bleich SN, Gortmaker SL. Increasing Caloric Contribution from Sugar Sweetened Beverage (SSBs) and 100\% Juices among US Children and Adolescents, 1988-2004. Official Journal of The American Academy of Pediatrics. 2008; 121(6): 1604-1614

[36] Perichart-perera O, Balas-nakash M, Rodríguez-cano A, Muñozmanrique C. Correlates of Dietary Energy Sources with Cardiovascular Disease Risk Markers in Mexican School-Age Children. Journal of American Dietetic Association. 2010;110(2):253-260

[37] Schulze MB, Manson JE, Ludwig DS, Colditz GA, Stampfer MJ, Willett WC. Sugar Sweetened Beverages, Weight Gain, and Incidence of Type 2 Diabetes in Young and Middle-Aged Women. American Medical Association. 2004;292(8):927-934

[38] Malik VS, Popkin BM, Bray GA, Despres J-P, Hu FB. Sugar Sweetened Beverage, Obesity, Type 2 Diabetes and Cardiovascular Disease Risk. National Institutes of Healh. 2010;83(2):101-108 